\title{
VISUAL AND EYE MOVEMENT FUNCTIONS OF THE POSTERIOR PARIETAL CORTEX
}

\author{
Richard A. Andersen \\ Department of Brain and Cognitive Sciences, Massachusetts Institute of \\ Technology, Cambridge, Massachusetts 02139
}

\section{INTRODUCTION}

Lesions of the posterior parietal area in humans produce interesting spatial-perceptual and spatial-behavioral deficits. Among the more important deficits observed are loss of spatial memories, problems representing spatial relations in models or drawings, disturbances in the spatial distribution of attention, and the inability to localize visual targets. Posterior parietal lesions in nonhuman primates also produce visual spatial deficits not unlike those found in humans. Mountcastle and his colleagues were the first to explore this area, using single cell recording techniques in behaving monkeys over 13 years ago. Subsequent work by Mountcastle, Lynch and colleagues, Hyvarinen and colleagues, Robinson, Goldberg \& Stanton, and Sakata and colleagues during the period of the late 1970s and early 1980 s provided an informational and conceptual foundation for exploration of this fascinating area of the brain. Four new directions of research that are presently being explored from this foundation are reviewed in this article.

1. The anatomical and functional organization of the inferior parietal lobule is presently being investigated with neuroanatomical tracing and single cell recording techniques. This area is now known to be comprised of at least four separate cortical fields.

2. Neural mechanisms for spatial constancy are being explored. In area 7a information about eye position is found to be integrated with visual inputs to produce representations of visual space that are head-centered 
(the meaning of a head-centered coordinate system is explained on $\mathrm{p}$. 13).

3. The role of the posterior parietal cortex, and the pathways projecting into this region, in processing information about motion in the visual world is under investigation. Visual areas within the posterior parietal cortex may play a role in extracting higher level motion information including the perception of structurc-from-motion.

4. A previously unexplored area within the intraparietal sulcus has been found whose cells hold a representation in memory of planned eye movements. Special experimental protocols have shown that these cells code the direction and amplitude of intended movements in motor coordinates and suggest that this area plays a role in motor planning.

\section{ANATOMICAL AND FUNCTIONAL ORGANIZATION}

The posterior parietal cortex comprises the caudal aspect of the parietal lobe (see Figure 1). This cortical area consists of the superior and inferior parietal lobules. Brodmann (1905) designated the superior parietal lobule area 5 and the inferior parietal lobule area 7 . Arca 5 contains exclusively somatosensory association cortex. Area 7 has been further subdivided into two areas based on cytoarchitectural criteria: a caudalmedial area designated 7a by Vogt \& Vogt (1919) or PG by von Bonin \& Bailey (1947) and a more lateral-rostral area designated $7 b$ (Vogt \& Vogt 1919) or PF (von Bonin \& Bailey 1947). The inferior parietal lobule includes not only the cortex on the gyral surface but also the cortex in the lateral bank of the intraparietal sulcus, the cortex in the anterior bank of the caudal third of the superior temporal sulcus, and even extends to include a small section of cortex on the medial wall of the cerebral hemisphere.

Description of precise homologies for areas in the posterior parietal cortices of monkeys and humans is difficult. Brodmann asserted that the superior parietal lobule of man was cytoarchitecturally comparable to the inferior parietal lobule of the monkey. If this were true then there would be no homologous area in the monkey to Brodmann's areas 39 and 40 , which comprise the inferior parietal lobule of humans. Von Bonin \& Bailey disagreed with Brodmann's scheme in the monkey and suggested that their areas PG and PF that comprise the inferior parietal lobule in monkey were equivalent to the inferior parietal lobule in man. The fact that lesions of the inferior parietal lobule produce similar visual disorders in monkey and man whereas lesions of the superior parietal lobule generally result in somatosensory disorders in the two species argues for von Bonin \& Bailey's view.

Based on functional differences and differing cortico-cortical con- 
nections and subcortical connections, the inferior parietal lobule has been found to contain at least four distinct subdivisions: areas 7b, LIP, MST, and $7 \mathrm{a}$. A flattened reconstruction of the cortex of the inferior parietal lobule and adjacent prelunate gyrus are pictured in Figure 1 with the various cortical areas of the inferior parietal lobule indicated in the figure.

\section{Area $7 b$}

A majority of the cells in area $7 \mathrm{~b}$ respond to somatosensory stimuli (Hyvarinen \& Shelepin 1979, Robinson \& Burton 1980a,b, Hyvarinen 1981, Andersen et al 1985c). Robinson \& Burton (1980a,b) reported a crude

A
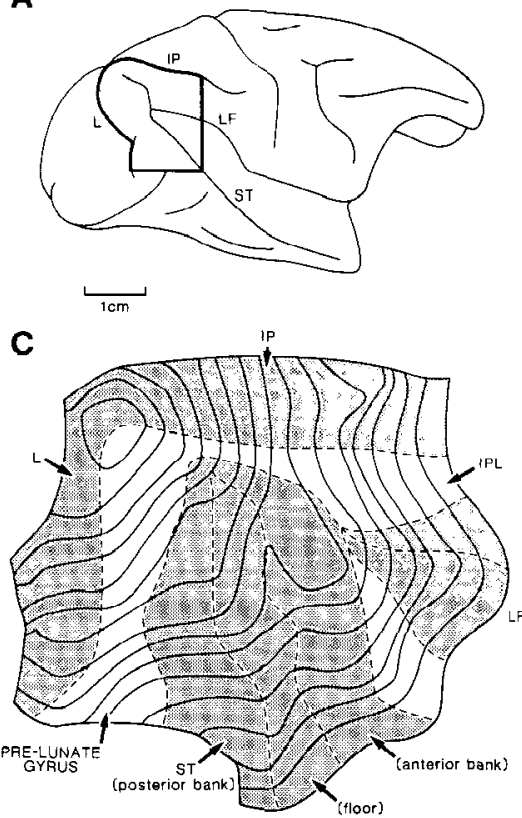

B

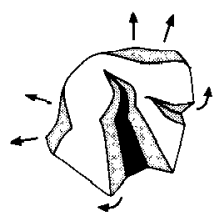

D

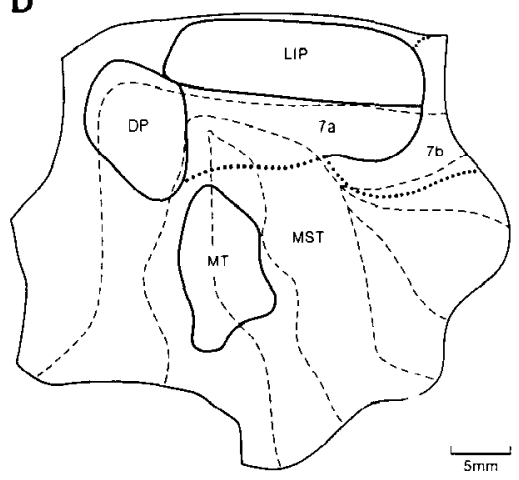

Figure I Parcellation of inferior parietal lobule and adjoining dorsal aspect of prelunate gyrus based on physiological, connectional, myeloarchitectural, and cytoarchitectural criteria. Cortical arcas are represented on flattened reconstructions of cortex. $(A)$ Lateral view of monkey hemisphere. Darker lines outline flattened area. (B) Same cortex isolated from the rest of the brain. Stippled areas, cortex buried in sulci; blackened area, floor of superior temporal sulcus (ST); arrows, movement of local cortical regions resulting from mechanical flattening. $(C)$ Completely flattened representation of same frontal sections through this area. $(D)$ Locations of several cortical areas. Dotted lines, borders of cortical fields not precisely determinable; DP, dorsal prelunate area; IP, intraparietal sulcus; IPL, inferior parietal lobule; L, lunate sulcus; LF, lateral fissure; LIP, lateral intraparietal area; MST, medial superior temporal area; MT, middle temporal area. From Andersen (1987). 
topographic arrangement of the body represented in area $7 \mathrm{~b}$, although the receptive fields of the cells were often very large and as a result obscured the topographic order. Cells have been studied in this area that are responsive to reaching and hand manipulation (Mountcastle et al 1975, Andersen et al 1985c).

A minority of the cells in this region $(10 \%)$ have also been reported to be responsive to visual or visual and somatosensory stimuli (Robinson \& Burton 1980a,b, Hyvarinen 1981). As would be expected, area $7 \mathrm{~b}$ has been found to possess cortico-cortical connections primarily with other areas involved in somatosensory processing. These other somatosensory areas include the insular cortex, and area 5 (Andersen 1987 for review). Area 7b also has been found to receive its primary thalamic input from the oral subdivision of the pulvinar (Asanuma et al 1985). This thalamic nucleus connects to other somatosensory areas such as area 5.

\section{Area LIP}

The lateral intraparietal area (LIP) is located in the lateral bank of the intraparietal sulcus. It appears to play a role in saccadic eye movements. Shubutani and colleagues (1984) have reported evoking saccades with electrical stimulation to the area at lower thresholds than to other regions they have examined in the posterior parietal cortex. However, the currents they used in area LIP were still rather high compared to those required to elicit eye movements from the frontal eye fields or superior colliculus. Andersen et al (1985a) have found many more saccade-related neurons in this area than in area 7a. Area LIP demonstrates a much stronger projection than that arising from area $7 \mathrm{a}$ to the frontal eye fields and superior colliculus (Barbas \& Mesulam 1981, Asanuma et al 1985, Lynch et al 1985), two structures involved in the generation of saccades. LIP is the recipient of inputs from several extrastriate cortical areas, including the middle temporal area (MT), a cortical field implicated in visual motion processing (Ungerleider \& Desimone 1986, Andersen 1987).

\section{Area MST}

Recent experiments suggest that the medial superior temporal area (MST) is specialized for motion analysis and smooth pursuit eye movements. Sakata and colleagues (1983) and Wurtz \& Newsome (1985) have found that most cells responding during smooth pursuit are located in this brain area. Sakata et al (1985) and Saito ct al (1985) have found that many cells in this area are sensitive to relative motion, responding to such parameters as rotation and size change. Lesions to MST produce deficits in smooth pursuit eye movements; the speed required to initiate smooth pursuit in order to match target speed is underestimated and the maintenance of 
pursuit is subsequently defective for tracking toward the side of the lesion (Dursteler et al 1986). Area MST has been shown to receive direct projections from several extrastriate visual areas, including area MT. It projects to area 7a and LIP (Maunsell \& Van Essen 1983, Seltzer \& Pandya 1984, Colby et al 1985, Siegel et al 1985, Andersen 1987).

\section{Area $7 a$}

Area 7a appears to play a role in spatial analysis through the integration of eye position and retinotopic visual information. A majority of the cells examined in this area have visual receptivc fields (Hyvarinen 1981, Motter \& Mountcastle 1981, Andersen et al 1987). Many of these visual cells also carry eye position signals and some display saccade-related activity (Andersen et al 1987). For many neurons visual excitability varies as a function of the position of the eyes in the orbit, that is, the angle of gaze. This gating of visual signals by eye position produces a tuning for locations in what is known as head-centered space (Andersen et al 1985b); these notions are described in more detail in the section on Spatial Constancy.

Area $7 \mathrm{a}$ has been found to have more extensive connections with highorder areas in the frontal and temporal lobes and the cingulate gyrus than do the other areas in the posterior parietal cortex. While $7 \mathrm{a}$ also projects strongly to the prefrontal cortex in and around the principal sulcus (area 46 of Walker), unlike area LIP, it is only weakly connected to the frontal eye fields (Barbas \& Mesulam 1981, Andersen 1987). Area 7a has very strong interconnections with the entire cingulate gyrus; the most dense connections are to area LC in the posterior half of the gyrus (Pandya et al 1981, Andersen 1987). In contrast area $7 b$ is connected primarily, if not exclusively, to area LA in the anterior aspect of the cingulate gyrus (Andersen 1987). Area 7a additionally demonstrates the most extensive connections of all the posterior parietal areas with the cortex that is buried in the superior temporal sulcus, including area MST (Andersen 1987).

Differences in connections define at least two additional visual areas: the ventral intraparietal area (VIP) located in the fundus of the intraparietal sulcus (Maunsell \& Van Essen 1983) and the dorsal prelunate gyrus which lies above area V4 (Asanuma et al 1985, Andersen 1987). The functional properties of the neurons in these areas have not yet been explored.

The above observations indicate that the monkey inferior parietal lobule can be subdivided into a larger somatosensory area essentially coextensive with $P F$, and several visual areas within $P G$.

\section{Visual Pathways into the Inferior Parietal Lobule}

Visual inputs into the inferior parietal lobule arrive from extrastriate cortex rather than directly from the primary visual cortex (V1) itself. A second 


\section{ANDERSEN}

possible source of input lies in the pathway from the retinorecipient areas of the superior colliculus and pretectum through the pulvinar into the inferior parietal lobule (IPL). Visual inputs from this pathway are likely to be of minor significance, however. The retinorecipient (superficial) layers of the superior colliculus project to the inferior pulvinar and to the ventral aspect of the lateral pulvinar (Benevento \& Fallon 1975, Benevento \& Standage 1983, Harting et al 1980, Trojanowski \& Jacobson 1975) but these areas of the thalamus do not project to the IPL (Asanuma et al 1985, Yeterian \& Pandya 1985). Area 7a receives its pulvinar input from the medial pulvinar (Asanuma et al 1985, Yeterian \& Pandya 1985), and it is only the deep, oculomotor layers (not the supcrficial visual layers) of the superior colliculus that project to the medial pulvinar. Also the medial pulvinar does not receive descending corticothalamic projections from other visual cortices (Bisiach \& Luzzatti 1978, Benevento \& Standage 1983, Harting et al 1980). Thus, with the exception of a minor projection from the pretectum (Benevento \& Standage 1983), no obvious visual inputs enter the medial pulvinar that could then be relayed up to area $7 \mathrm{a}$. Areas DP and LIP receive their principal thalamic inputs from the visual nonretinotopic dorsal aspect of the lateral pulvinar (Asanuma et al 1985). The lateral pulvinar receives inputs only from the oculomotor part of the superior colliculus and from the pretectum, and its cells are weakly driven by visual stimuli (Benevento et al 1977, Benevento \& Standage 1983, Harting et al 1980).

The flow of visual processing can be presumed by determining the laminar distributions of the sources and terminations of corticocortical projections in visual cortex (Rockland \& Pandya 1979, Maunsell \& Van Essen 1983). Early in the visual pathway, feedforward projections originate from cell bodies located in the supragranular layers and end in terminals in layer IV and lower layer III. Feedback projections originate in the supragranular and infragranular layers and end most densely in layers I and VI. The hierarchical progression of visual processing can be traced from area V1 at the base of the hierarchy to area $7 \mathrm{a}$ at the top if the following modification is considered for the projections into the inferior parietal lobule: feedforward projections originate in both superficial and deep cortical layers but still end predominantly in layer IV and lower layer III.

The routes of visual input into the inferior parietal lobule (dashed square) are shown in Figure 2, arranged in a hierarchical structure determined by the laminar distribution of the sources and terminals of the connections. Each line represents reciporcal corticocortical connections between fields. It can be seen that multiple visual pathways project into the inferior parietal lobule and that area 7 a represents the pinnacle of the hicrarchy. 


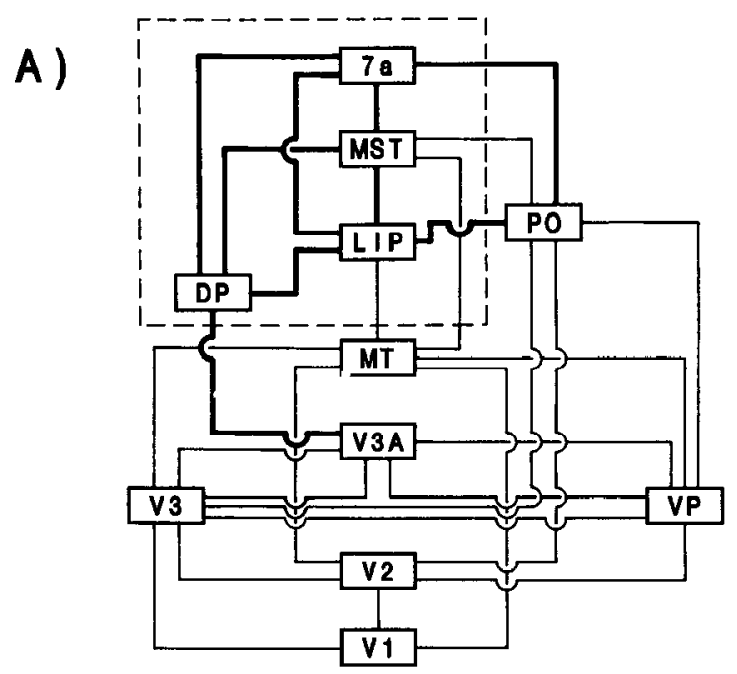

B)

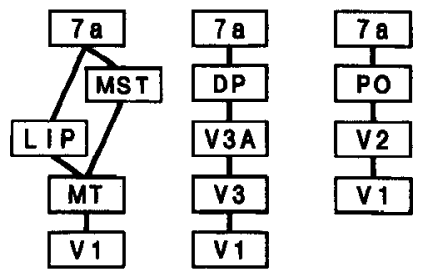

Figure $2(A)$ Hierarchy of visual pathways from area V1 to the inferior parietal cortex determined by laminar patterns of sources and terminations of projections. Dashed box, cortical areas of inferior parietal lobule and dorsal aspect of prelunate gyrus. (B) Three of the shortest pathways for visual information to travel from area Vl to area $7 \mathrm{a}$. From Andersen (1987).

Figure $2 b$ demonstrates the shortest routes from area $\mathrm{V} 1$ to area $7 \mathrm{a}$; each of these paths must pass through two or three extrastiate visual areas prior to arriving at area $7 \mathrm{a}$. Of particular importance to motion processing is the pathway that begins in area VI and passes through areas MT and MST to area $7 \mathrm{a}$. This pathway and its role in motion processing are discussed in the next section.

\section{MOTION ANALYSIS}

A substantial body of evidence suggests that visual motion analysis is treated by specific brain regions. There are several accounts of brain lesions 


\section{ANDERSEN}

in humans that produce deficits in motion perception without deficits in other forms of vision. Recording experiments by a number of investigators have pointed to areas in the dorsal aspect of extrastriate cortex that may be specialized for motion analysis. Taken together, these various recording experiments delineate a pathway that originates in primary visual cortex and terminates in posterior parietal cortex. The anatomical determination of this presumed motion processing pathway is an important first step in understanding the neural mechanisms that account for motion perception.

At the beginning of the pathway, direction-selective cells in layers $4 \mathrm{~b}$ and 6 of primary visual cortex project to the middle temporal area (MT) (V5 of Zeki). Results of recording experiments in MT indicate that nearly all of the cells in this area are direction selective compared to only about $20 \%$ in area V1. A functional architecture for direction selectivity exists in MT similar to the functional architecture described for orientation in V1 (Albright et al 1984). The neurons of area MT also exhibit interesting responses that may account for certain features of motion perception. For example, some cells are selective for the global direction of motion of patterns rather than for the motion of those components of the pattern that occur orthogonally to the preferred orientation of the neurons (Movshon et al 1985). Other cells are speed invariant over a wide range of spatiotemporal frequencies (Movshon 1985). MT cells also exhibit opponent center/surround organizations for direction selectivity; strong inhibition results when motion in the surround is in the same direction as motion in the center (Allman et al 1985, Tanaka et al 1986). These surround mechanisms are quite large and often include the entire visual ficld. Some have speculated that these cells play a role in processing motion parallax (important for extracting depth from motion cues) or in distinguishing the external movement of objects in the world from motion generated by the eyes moving in their orbits (Allman et al 1985). While these data have led to the suggestion that area MT is specialized for processing motion, it had not been shown until recently that damage restricted to area MT disrupts motion perception.

Area MT then projects to the immediately adjacent medial superior temporal (MST) area, which is located in the posterior parietal cortex within the anterior bank of the superior temporal sulcus. Recording experiments suggest that MST contains cells that are selective for rotation and expansion of velocity fields (Saito et al 1985, Sakata et al 1985, 1986). Area MST in turn projects to area $7 \mathrm{a}$ in the posterior parietal cortex. Cells in this region demonstrate an opponent direction organization with respect to the fixation point, a feature that has been suggested to be important to the analysis of visual flow fields during locomotion (Motter \& Mountcastle 1981). 
There is evidence for a functional hierarchy for visual motion analysis within the dorsal extrastriate cortex. Area MT processes more complex aspects of motion than do the direction-selective cells of V1, and in turn areas MST and 7a appear to analyze still more complex aspects of motion, such as aspects of structure-from-motion.

\section{Motion Psychophysics}

In order to understand the functional processes that occur along this pathway, Andersen and colleagues, Wurtz and colleagues, and Newsome and colleagues employed a strategy whereby the ability of monkeys to perceive various aspects of motion is first determined psychophysically. Lesions are then made at different locations in the motion pathway, and the monkeys are retested to determine the contribution of the different cortical areas to movement perception. These psychophysical and lesion experiments are described in the next two sections.

Until recently, no psychophysical experiments had been performed to measure the ability of monkeys to see motion. Andersen and colleagues (Golomb el al 1985, Siegel \& Andersen 1988, Andersen \& Siegel 1988) undertook these psychophysical studies and chose to examine two types of relative motion perception in monkeys - the ability to detect shear motion and the ability to detect two- and three-dimensional structure in velocity fields. The spatio-temporal integration characteristics of structurefrom-motion perception were also examined. The results of these experiments suggest that the brain forms neural representations of surfaces by using structure-from-motion information.

In our first psychophysical investigations, Golomb et al (1985) studied the detection of shearing motion with psychophysical tasks in monkeys and humans. Shearing motion is a class of relative motion in which the change in direction of motion occurs along the axis orthogonal to the direction of motion. Because this form of motion accounts for depth perception from motion parallax, it is of great physiological importance and also provides a cue for the recognition of foreground versus background using motion discontinuities. Recording experiments in area MT of monkey (Allman et al 1985), the pigeon optic tectum (Frost \& Nakayama 1985), and area V2 of monkey (Orban et al 1986) have identified neurons with receptive fields that have opponent-direction center-surround organization; these cells would be maximumly active for a shear stimulus. Due to its importance, a large body of psychophysical data has already been collected in humans with respect to shear motion detection abilities (Nakayama \& Tyler 1981, Nakayama et al 1984, Nakayama 1981, Rogers \& Graham 1979, 1982), making comparison of our results in the monkey and human with those of previous work possible. 
The shear motion stimulus consisted of a standing transverse wave of sinusoidly varying spatial and temporal frequency. Thresholds for detection of shear were measured for various combinations of spatial frequency, temporal frequency, and amplitude. For all these combinations of parameters, humans and monkeys showed similar thresholds. Figure 3 shows an example of the stimulus and the psychophysical results.

A second type of motion perception we have examined is the ability of monkeys and humans to detect structure in velocity fields, i.e. structure from motion. We have recently developed a novel set of stimuli that

A.

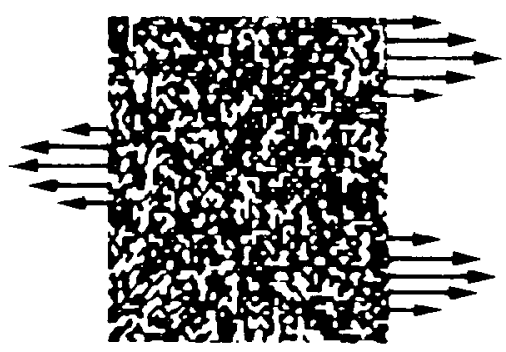

B.

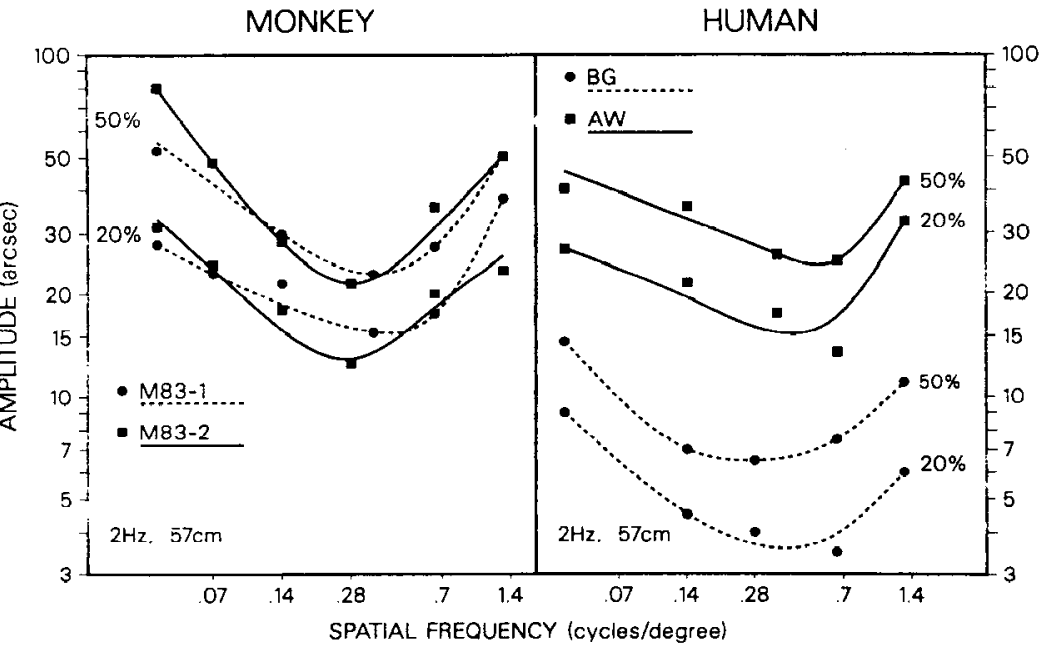

Figure 3 A random dot display that undergoes a horizontal shearing motion. Each horizontal row of dots moves as a rigid unit with a velocity that is a sinusoidal function of the vertical position of the row. The arrows represent the instantaneous velocity vectors. Note that the direction of motion reverses at the zero crossings of the sinusoidal velocity function. From Golomb et al (1985). 
test the ability of subjects to detect structure in velocity fields without introducing confounding positional cues. Three types of structures have been examined using these stimuli with both monkey and human subjects (Siegel \& Andersen 1988, Andersen \& Siegel 1988). Two types of twodimensional structures (expansion and rotation) and a three-dimensional structure [a revolving hollow cylinder (Figure $4 a$ )] have been developed for these tasks. The subjects are required to perform a reaction-time task in which they must detect the transition from an unstructured velocity field to a partial or completely structured velocity field. The structured and unstructured displays contain the same vectors; however, in the unstructured case the vectors have been randomly shuffled, thus destroying structure.

Figure $4 b$ shows psychometric functions for the 3-D cylinder detection task for a monkey and a human in which performance is plotted as a function of the percentage of structure in the display. It can be seen that the psychometric functions for the two species are quite similar. Such equivalent performance was seen in monkeys and humans for both the 2-D stimuli detection tasks as well.

Having established that out subjects were able to detect three-dimensional structure from the velocity fields in our psychophysical paradigm, we then examined how information about structure-from-motion might be integrated over space and time by the visual system. The important theoretical groundwork for this problem was laid by Ullman (1979) when he proved in his structure-from-motion theorem that "given three distinct orthographic views of four non-coplanar points in a rigid configuration, the structure and motion compatible with the three views are uniquely determined." Ullman (1979) realized that his theorem described an algebraic limit and that the brain may require more points and frames, since it is a "noisy" system, and it might also use a less than optimum algorithm. In this set of experiments the question of spatial integration was investigated by varying the density of the points, whereas the temporal integration problem was investigated by varying the point life times in the 3-D cylinder task.

The performance of a monkey and a human subject for different point lives is illustrated in Figure $4 c$ with the standard 128 points present in the display; it can be seen that below $100 \mathrm{msec}$ the human's performance was poor and below $50 \mathrm{msec}$ the monkey's was poor. Using a fixed point life of $532 \mathrm{msec}$ and studying the effect of the number of points present in the display, the human and monkey subjects both showed poor performance below 32 points. Interestingly there was space-time trading such that equivalent performance could be achieved with longer lifetimes and fewer points or vice versa. These experiments demonstrate that motion infor- 
388

A.

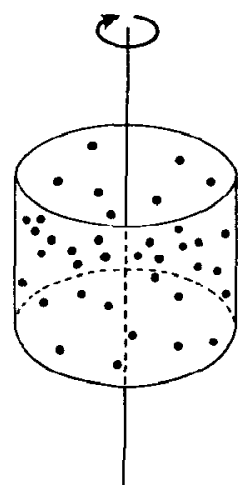

C.

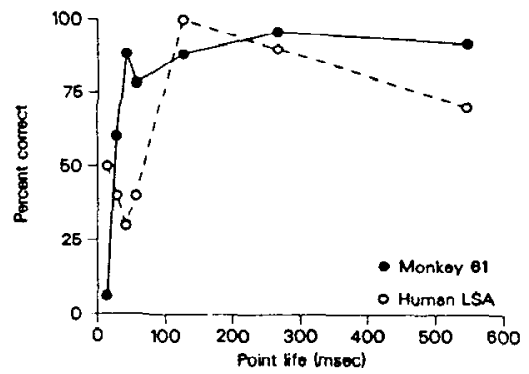

B.

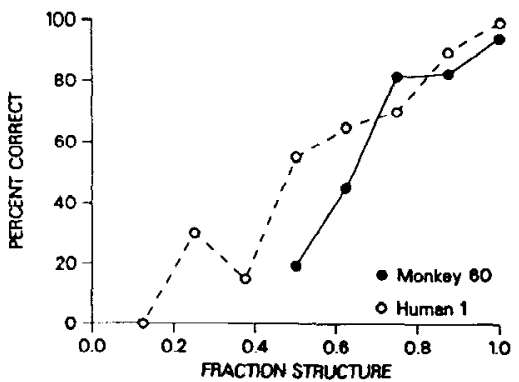

D.

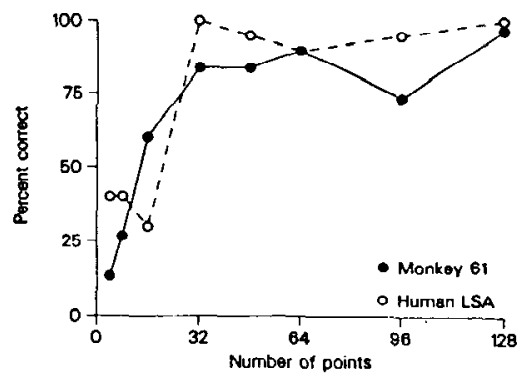

Figure $4(A)$ The 3-D structure-from-motion stimulus. Dots are projected onto the surface of a revolving hollow cylinder. $(B)$ The percentage of trials in which the subject released the key within the requisite time window is plotted as a function of the fraction of structure. The human and monkey have similar psychometric functions that have a decrease in detection when the fraction of structure is approximately less than 0.65 . Statistical analysis using the $\chi^{2}$ for independent samples showed no difference between the human and monkey subjects $(P<0.05)$. In this experiment, 128 points were viewed with a point lifetime of $532 \mathrm{msec}$; the cylinder revolved at $35 \mathrm{deg} / \mathrm{sec}$; the display was refreshed at $35 \mathrm{~Hz}$. The ability of the monkey and human subjects to perform the task depended on both the point lifetime $(C)$ and number of points $(D)$ of the display. The significant difference in minimal point lifetime required to perform the task successfully between the human and primate subject is likely due to the additional training given the monkey subjects. It can be seen that decreasing the number of points makes it more difficult for the subjects to perform the task. In figures $(C)$ and $(D)$, the fraction of structure was 0.875 ; the refresh rate was $70 \mathrm{~Hz}$; the cylinder revolved at 35 $\mathrm{deg} / \mathrm{sec}$. From Siegel \& Andersen (1988). 
mation is integrated in both time and space to form neural representations of three-dimensional surfaces.

These space-time integration experiments provide information on the neural mechanisms responsible for computing structure-from-motion. An algorithm proposed by Ullman (1984) required the brain to track continuously the location of individual points in absolute coordinates to determine whether their trajectories conformed to the movement of a rigid object. Thus the brain, by the algorithm, would be solving algebraic equations using the points in the image. We know from the above experiments that the brain does not require continuously visible points to compute structure from motion, indicating that at least under these conditions the brain uses a different algorithm. The reaction time data indicate that the 3-D cylinder structure-from-motion computation required several hundreds of milliscconds. Therefore each point would have to be tracked over an extended period of time. The time integration experiments showed good performance when points were visible for only $100 \mathrm{msec}$ and were then replotted at random new positions, making any continuous, point-bound computation impossible. These results indicate that a 3-D surface can be computed by using a large number of intermittent sampling points across that surface.

\section{Area MT Plays an Important Role in the Perception of Motion}

Results from recent lesioning experiments establish area MT as part of a motion processing system responsible for the perception of motion. Equally interesting is the observation that after at least small area MT lesions the perception of motion recovers in a matter of days.

Newsome et al (1985) first tested the effect of MT lesions on smooth pursuit eye movements, a behavior requiring motion analysis. They discovered that small ibotenic acid lesions placed at retinotopically identified loci in area MT resulted in defects of smooth pursuit. During the early, so-called "open loop" stage of tracking the animals underestimated the target speed. The deficit was specific for the retinal locus of the lesion, thus indicating a sensory rather than a motor defect. Since the animals could make saccades accurately to the retinotopic locus of the lesion, the deficit was specific for motion perception and was not due to a general blindness.

These important experiments did not directly establish that the monkeys were unable to see motion, but rather that they could not use this information to make smooth pursuit eye movements. Two recent studies have shown directly that the perception of motion is in fact disrupted with area MT lesions. In the first of these two experiments Siegel \& Andersen trained 
monkeys to perform motion psychophysical tasks and obtained prelesion thresholds for the detection of shear motion and structure-from-motion (Andersen \& Siegel 1986, 1988, Siegel \& Andersen 1986). Small ibotenic acid lesions were then made to area MT; these produced an eight-fold increase in shear motion thresholds. As expected, the increase in thresholds was found only for those areas in the visual field that corresponded to the retinotopic locus of the lesion in area MT (Figure 5). The deficit was specific for motion, since contrast sensitivity thresholds were also tested and found not to be affected at the same locations in the visual field as the motion deficit. Since the animals were required only to determine whether or not they saw motion, and not any of the parameters of the motion such as stimulus direction, it was interpreted that the animals had a deficit in the detection of motion. Thus restricted lesions to area MT produced motion scotomas in the visual field. Figure 5 illustrates the most interesting finding that the deficits were transient, recovering in four to five days and demonstrating a similar time course to the recovery as the tracking deficit recorded in the experiments of Newsome et al (1985). The effects of MT lesions on structure-from-motion thresholds were also tested in one hemisphere. The task the monkey performed was the 3-D revolving hollow cylinder task detailed in the preceding section of this article. As with the psychophysical studies, the amount of structure in the stimulus was varied to generate psychometric functions. The animal could not do this structurefrom-motion task after the area MT lesion even when the velocity field was completely structured. Moreover, the structure-from-motion deficit remained for 23 days (at which time the experiment was terminated), long after the motion detection thresholds had returned to normal.

In a second set of experiments, Newsome \& Pare $(1986,1988)$ tested the ability of monkeys to determine the direction of correlated motion imbedded in noise. They then made ibotenic acid lesions to area MT and found large increases in the measured motion thresholds. These lesions did not affect contrast thresholds. They also found the motion perception deficit to be transient; thresholds recovered to normal values within a few days.

The above experiments indicate that area MT is a component of a motion processing system important for perceiving motion. The thresholds recorded for the shear detection tasks after MT lesions were so large that it is possible that the animals were using positional cues to solve the task at very large amplitudes of shear. The transient nature of the deficit is a common feature of all the experiments, and is seen for pursuit eye movements, motion detection, and direction detection. The rccovery may result either from a reorganization of area MT or from recruitment of some parallel pathway which normally does not play a primary role in motion 


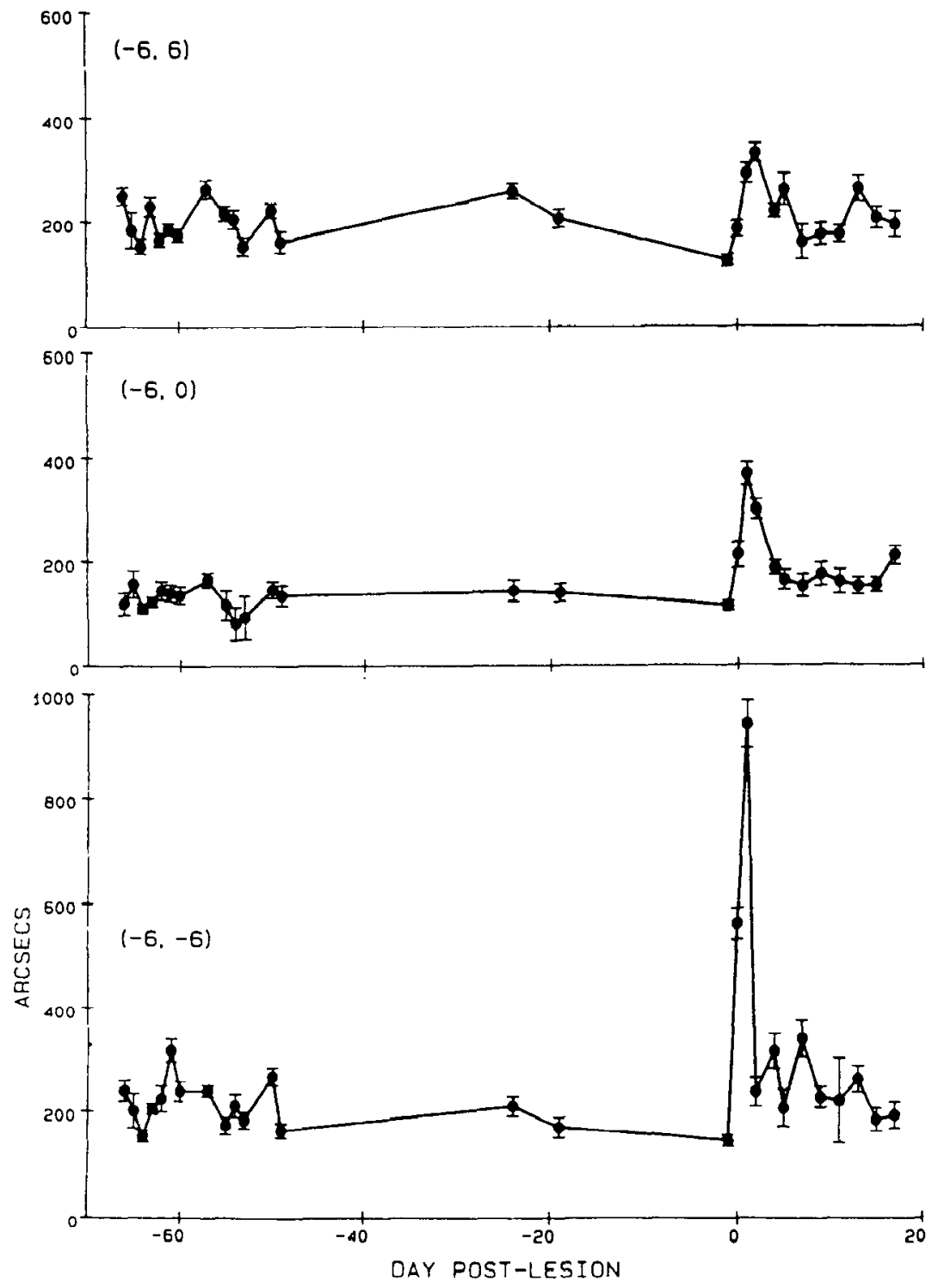

Figure 5 The effect of ibotenic acid lesions in area MT on shear motion thresholds. Fifty percent hit rates are plotted from psychometric curves in which spatial and temporal frequency is held constant and amplitude is varied. In this case the lesion was placed in the lower visual field representation of area MT in the contralateral (right) hemisphere. Note that the greatest effect is focused at the lower field location; thresholds increase after one day to over 900 arc sec. Also note that the thresholds recover rapidly in the matter of a few days. From Andersen \& Siegel (1988). 
perception. These two possibilities could be tested by completely destroying area MT. If the motion thresholds do not return, the recovery is a result of the reorganization of area MT; if they do still recover, parallel pathways are involved in the recovery.

An interesting question regarding recovery is whether training is required for it to occur. The monkeys perform thousands of trials on the motion tasks before the thresholds recover. If the animals were to be placed in the dark immediately after MT lesions and brought out a week later, would the thresholds have recovered spontaneously or would they still be elevated, indicating that retraining has played a significant role?

The single observation of a more permanent deficit in structure-frommotion perception, if it is reproduced in subsequent experiments, will indicate that $(a)$ the structure-from-motion computation is performed in area MT and no other pathway can assume this task, or alternatively $(b)$ some other area such as area MST requires preprocessing for the structurefrom-motion computation that only area MT can provide.

\section{SPATIAL CONSTANCY}

Because the projection from the eyes to the primary visual cortex is retinotopic, an "image" of whatever the eyes are looking at appears over the visual cortex, and this "image" changes as the eyes view different parts of the world. Such retinotopic mapping is widespread throughout the visual system. Two reasons to believe that the brain contains non-retinotopic representations of visual space, however, are as follows:

1. When we move our eyes, our perceived visual world is stationary. This result suggests that eye position information is used to compensate for movements of the visual image focused on the retinas. Although it could be argued that purely sensory signals are used to stabilize the visual world (i.e. that a complete translation of the retinal image indicates an eye movement and not movement of the world), other evidence indicates that this explanation is unlikely. Moving the eyes passively, which generates the same retinal stimulation as willed eye movements, produces the impression that the world has moved.

2. Motor movements such as reaching are made accurately to visual targets without visual feedback during the movement. This observation indicates that the motor system uses representations of the visual stimulus mapped in body-centered rather than retinal coordinates.

A most likely area of the brain to find non-retinotopic representations of visual space is the posterior parietal cortex. Lesions in this region in humans produce a syndrome called visual disorientation in which patients 
cannot reach accurately to visual targets and have difficulty navigating around seen obstacles. These patients are not blind but appear to be unable to associate the locations of what they see with their body position.

Recent recording experiments have begun to establish how visual space is represented in area $7 \mathrm{a}$ of the posterior parietal cortex (Andersen et al $1985 \mathrm{~b}$ ). Visual receptive fields were first mapped in these experiments with monkeys fixating at different eye positions. The heads were fixed simplifying the coordinate space to a head-centered frame. Two possible results under these conditions would be either that the retinal receptive fields move with the eyes so that visual space is mapped in retinal coordinates, or that the receptive fields do not move with the eyes but remain constant for a location in head-centered space. Neither representation was found. Instead the receptive fields were found to move with the eyes (i.e. they were retinotopic), but the responsiveness of these receptive fields to retinotopically identical stimuli varied as a function of the eye position (Figure 6).

The interaction of eye position and retinal position was found to be multiplicative. The activity of area $7 \mathrm{a}$ neurons to visual stimuli was described as a gain that was a function of eye position, multiplied by the response profile of the retinal receptive field. This interaction produces a tuning for locations of targets in head-centered space but in a fashion dependent on eye position. To illustrate this result in a simple example, consider a cell that has a receptive field $10 \mathrm{deg}$ to the left and is only responsive when the animal looks 10 deg to the right from straight ahead. Such a cell will respond only for stimuli located straight ahead in headcentered space (spatial tuning) but only if the animal is looking $10 \mathrm{deg}$ to the right (eye-position dependence). Cells have never been found that code the location of a target in space in an eye-position-independent fashion; it can be shown, however, that sufficient information for such a coding is present in the population response of area 7 a neurons. How such a distributed code is interpreted by the brain is an open question. One possible solution would be the presence of a topographic organization for spatial tuning in the cortex; however, so far recording experiments have not revealed such a map and the present data suggest that if such a map exists it is likely to be either crude or highly fractured.

Recently a parallel network model was created by Zipser \& Andersen (1988, Andersen \& Zipser 1988) that learns spatial location by combining eye position and retinal position inputs. The model is a three layer network trained for spatial location using a back-propagation learning algorithm. This mathematical model generates receptive field properties in its middle layer units that are similar to those found for actual posterior parietal neurons. Figure 7 illustrates the model. The first, input layer consists of 


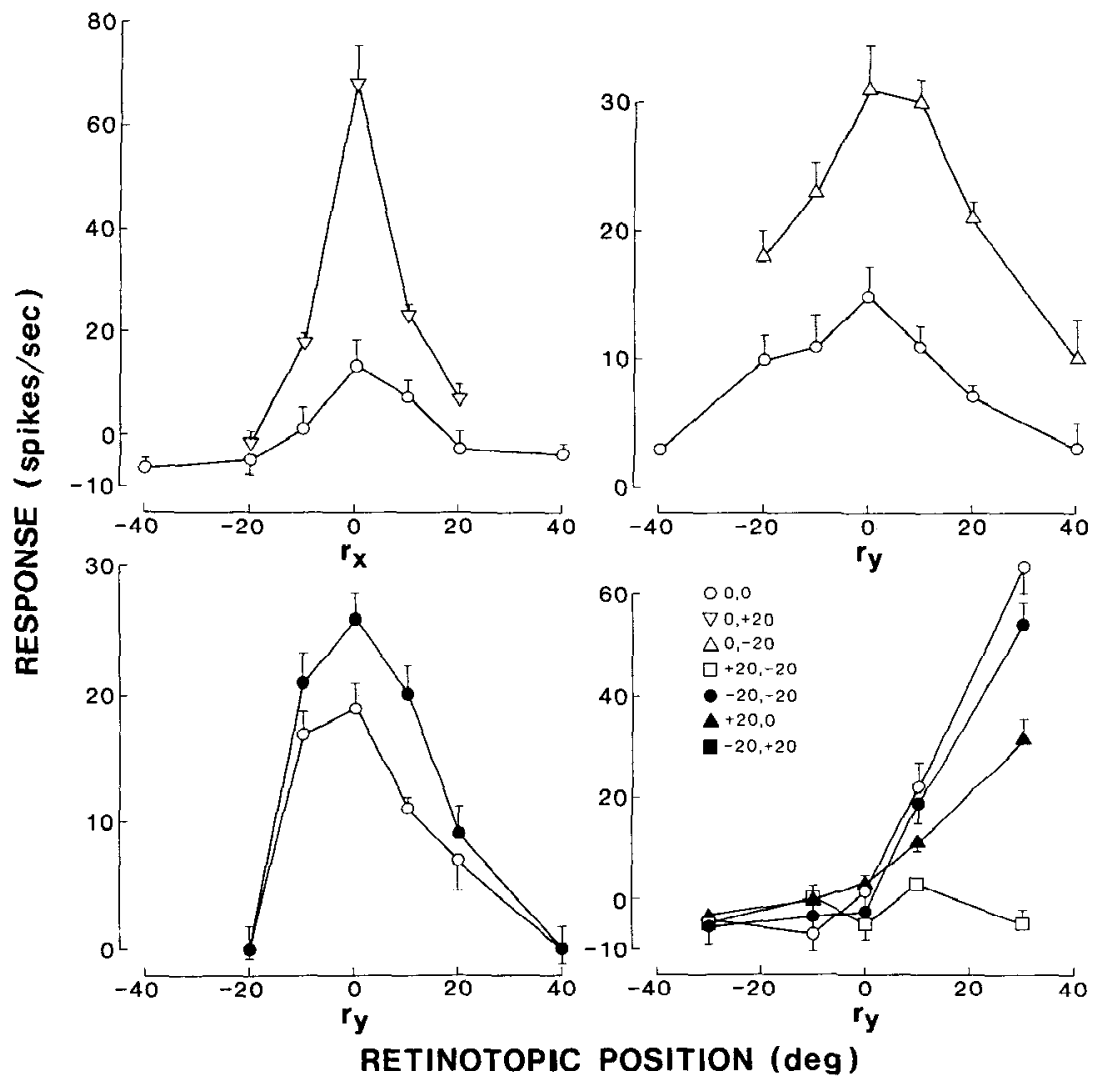

Figure 6 Mean response rates for different eye positions plotted in retinal coordinates along horizontal $\left(r_{\mathrm{x}}\right)$ or vertical $\left(r_{\mathrm{y}}\right)$ axes passing through the centers of the receptive fields of four neurons; each graph shows data for one neuron. Each point represents the mean response ( + or - standard error) to eight repetitions of the stimulus presented at the same retinal location. A randomized block design was used to present stimuli to different retinal locations in the receptive field of each cell. The reported response at each retinal location is equal to the activity during the presentation of the stimulus minus the background activity determined before the stimulus presentation. From Andersen et al (1985).

64 units in an 8 by 8 array that samples at equidistant points from a continuous two-dimensional retinal field and 4 sets of eye position inputs that code horizontal and vertical eye positions similar to the eye position cells found in area 7a. The intermediate layer has 9 units (and in some simulations up to 36 units) that receive inputs from all the input units and in turn project to either of two representations in the output layer that code location in head-centered space for any pair of arbitrary retinal and 
eye position inputs. After training is complete the middle layer units have receptive fields that remain retinotopic, but their activity becomes modulated by eye position in a manner similar to the recording data from area $7 \mathrm{a}$ neurons. The visual receptive fields of the model cells appear very similar to arca $7 \mathrm{a}$ fields, as they are large and occasionally complex but smoothly varying in shape.

These interesting results show that the trained parallel network and the posterior parietal cortex compute coordinate transformations in the same way. The network model was used to program an algorithm for solving the problem using a parallel architecture; however, that the network arrives at the same solution as area $7 \mathrm{a}$ does not mean that the solution was achieved by the same learning algorithm in the brain; i.e. back propagation. Moreover, in its striclest sense, back propagation could never be used by the brain, since it requires information to pass rapidly backwards through synapses. It will be important to investigate other parallel networks that have more realistic structures and mechanisms analogous to those found in the brain to determine how they might produce this form of distributed coding.

The model results suggest that the posterior parietal cortex may learn to associate visual inputs with eye position. This neural coding may be an example of a distributed associative memory. The spatial code in the model is by definition non-topographic, and yet it can be interpreted by the brain because it was learned and thus became an inherent property of the synaptic structure of the network. This learning mechanism suggests that area 7 a need not require a topography for spatial tuning in order to read out eye-position-independent spatial locations, although it also does not rule against one. Finally, the similarity of the retinal receptive fields of the network units and those of the cells suggests that parietal neurons may have access to the entire retina (as a result of the multistage divergence of the cortico-cortical projections from $\mathrm{V} 1$ to area $7 \mathrm{a}$ ) and that the receptive fields that eventually develop for area 7 a neurons are a result of competition during the learning process.

\section{ROLE OF PARIETAL LOBE IN VISUAL-MOTOR INTEGRATION}

The pioneering neurophysiological studies by Mountcastle and colleagues showed that the cells of the posterior parietal cortex have activity correlated with the motor and oculomotor behaviors of the animals (Mountcastle et al 1975, Lynch et al 1977). They proposed a command hypothesis for the function of the posterior parietal cortex that stated that this area synthesized sensory and motivational information from several cortical 
A Annual Reviews

www.annualreviews.org/aronline

396

ANDERSEN

areas and issued commands of a general nature for motor behaviors. In a subsequent study by Robinson et al (1978) it was found that many of these same neurons responded to sensory stimuli. They argued that the motorrelated activity seen by Mountcastle and colleagues was a result of sensory stimulation, either from the targets for movement or as a result of sensory

A

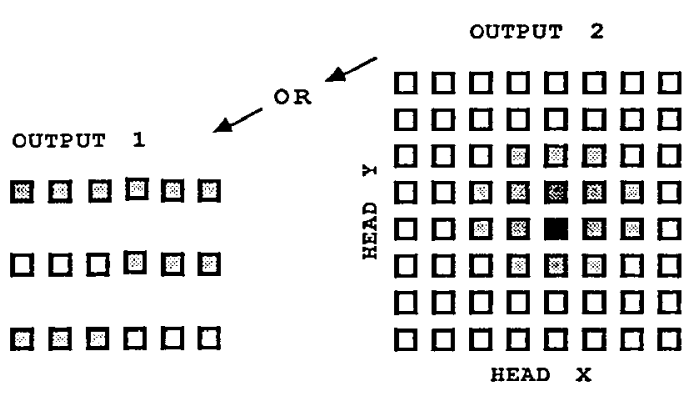

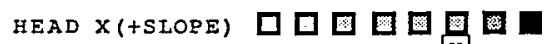

HIDDEN

UNITS

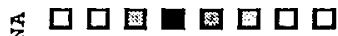

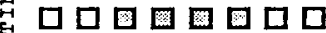

䊆 ㅁㅁㅁㅁㅁำ

ㅁㅁㅁㅁ

ㅁㅁㅁㅁ

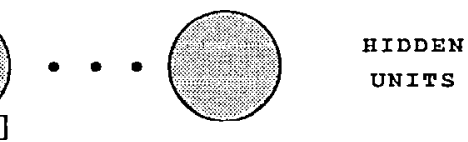

RETINA $x$

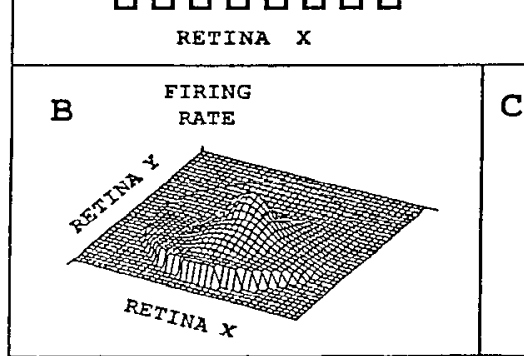

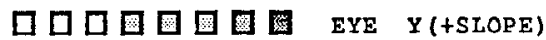

ロロロロロロロロ EYE X(-SLOPE)

圆口曰日回圆圆图 EYE X (tSLOPE)

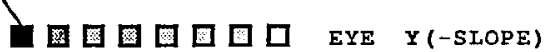

ㅁㅁㅁㅁ

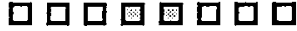

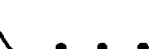

(1)

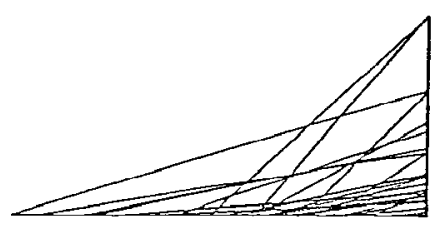

急田

EYE-POSTTION 
stimulation due to the movement. They also found that the responses to sensory stimuli were often enhanced if those stimuli were behaviorally relevant, and they proposed that the parietal lobe was important for attentional rather than motor command functions.

A number of investigators have subsequently designed experiments to separate sensory from motor-related responses, which were generally linked in the earlier studies (Sakata et al 1980, 1983, Andersen et al 1987, Wurtz \& Newsome 1985, Bioulac \& Lamarre 1979, Seal et al 1982, Seal \& Commenges 1985). Neurons generally have both sensory and movementrelated responses. Cells responding to reaching behavior also have somatosensory inputs, and cells responding to smooth pursuit, saccades, or fix-

Figure 7 (A) Back propagation network used to model area $7 \mathrm{a}$. The visual input consists of 64 units with Gaussian receptive fields with $1 / \mathrm{e}$ widths of $15 \mathrm{deg}$. The center of each receptive field occupies a position in an 8 by 8 array with $10 \mathrm{deg}$ spacings. The shading represents the level of activity for a single spot stimulus. The darker shading represents higher rates of activity. The units have been arrayed topographically. for illustrative purposes only; this pattern is not an aspect of the model, since each hidden unit receives input from every one of the 64 retinal input units. The eye position input consists of 4 sets of 8 units each. Two sets code horizontal position (one for negative slope and one for positive slope), and two sets code vertical position. Shading represents the level of activity. The intercepts have been ordered for illustrative purposes only and do not represent information available to the hidden layer. Each eye position cell projects to every unit in the hidden layer. Two output representations were used; the Gaussian output format is shown on the right and the monotonic format on the left. The Gaussian format units have Gaussian-shaded receptive fields plotted in head-centered coordinates. They have $1 / \mathrm{e}$ widths of $15 \mathrm{deg}$ and are centered on an 8 by 8 array in head coordinate space with 10 deg spacings. The monotonic format units have firing rates that arc a lincar function of position of the stimulus in head-centered coordinates. There are four sets of 8 units with two sets of opposite slope for vertical position and two sets for horizontal position in head-centered coordinates. Again, shading represents the degree of activity, and the topographic ordering is for illustrative purposes only. The small boxes with w's indicatc the location of the synapses whose weights are trained by back propagation. Each hidden unit projects to every cell in the output layer.

The output activity of the hidden and output layer units is calculated by the logistic function: output $=1 /\left(1-\mathrm{e}^{- \text {net }}\right)$ where net $=$ (wcighted sum of inputs $)+$ threshold. The arrow for the connections represents the direction of activity propagation; error was propagated back in the opposite direction. The back propagation proccdurc guarantees that the synaptic weight changes will always move the network toward lowcr error by implementing a gradient descent in error in the multi-dimensional synaptic weight space.

(B) Area 7 a visual neuron receptive field with a single peak near the fovea. Visual eells that had no eye position related activity or modulation of their responses by eye position were used to model the retinal input to the network.

(C) A composite of 30 area 7 a eye position units whose firing ratcs are plotted as a function of horizontal or vertical eye deviation. The slopes and intercepts are experimental values for eye position neurons. From Zipser \& Andersen (1988). 


\section{ANDERSEN}

ations also respond to visual stimuli. From these findings has emerged the concept that the parietal lobe should not be viewed as primarily a sensory or primarily a motor structure (Andersen 1987). Rather it apparently occupies a location somewhere between these two points, integrating sensory information to be used for the formulation of motor behaviors. Put quite simply, the area is involved in sensory-motor integration.

As mentioned above, a functional segregation appears to exist within the posterior parietal cortex (Hyvarinen 1981, Andersen et al 1985a,c); area MST contains cells responding to smooth pursuit, area $7 \mathrm{~b}$ contains the reach cells, area LIP is involved in saccades, and area 7 a contains many of the space-tuned and fixation neurons.

\section{Area LIP and its Role in Motor-planning}

An area has recently been discovered within the lateral bank of the intraparietal sulcus (the lateral intraparietal area-LIP) that appears to play a role in programming saccadic eye movements. This area is similar to the frontal eye fields in many respects, having many cells that fire before saccades and code eye movements in motor coordinates (Gnadt \& Andersen 1986, 1988, Andersen \& Gnadt 1988).

Gnadt \& Andersen have recently found that many of the LIP neurons have memory-linked activity (Gnadt \& Andersen 1988, Andersen \& Gnadt 1988). The memory-related responses are present in saccade tasks in which the animal must remember, in total darkness, the spatial location of a briefly flashed target for up to $1.6 \mathrm{sec}$ before making an eye movement to that location (Figure 8). The cells become active 50 to $100 \mathrm{msec}$ after the onset of the flash and remain active in the absence of any visual stimuli until the saccade is made. Thus, these neurons appear to be acting as latches, maintaining a steady rate of firing during the entire period that the saccade is withheld.

This interesting response property can be interpreted in three possible ways: (a) that it represents the memory of the retinotopic locus of the stimulus, $(b)$ that it codes the memory of the spatial location of the stimulus, or $(c)$ that it represents the memory of the movement that the animal intends to make. These three alternatives have been experimentally tested by asking in what coordinate frame the memory-linked response is represented. Using special tasks that separate sensory from motor coordinates, Gnadt \& Andersen found that these cells encode the intended amplitude and direction of movements in motor coordinates (Gnadt \& Andersen 1988, Andersen \& Gnadt 1988). Thus the cells hold in register the intent to make movements of a particular metric. This observation suggests that area LIP has activity related to aspects of motor planning. 
A. Target

Fixation
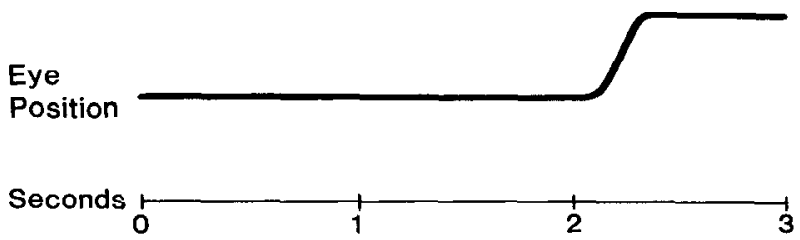

B.

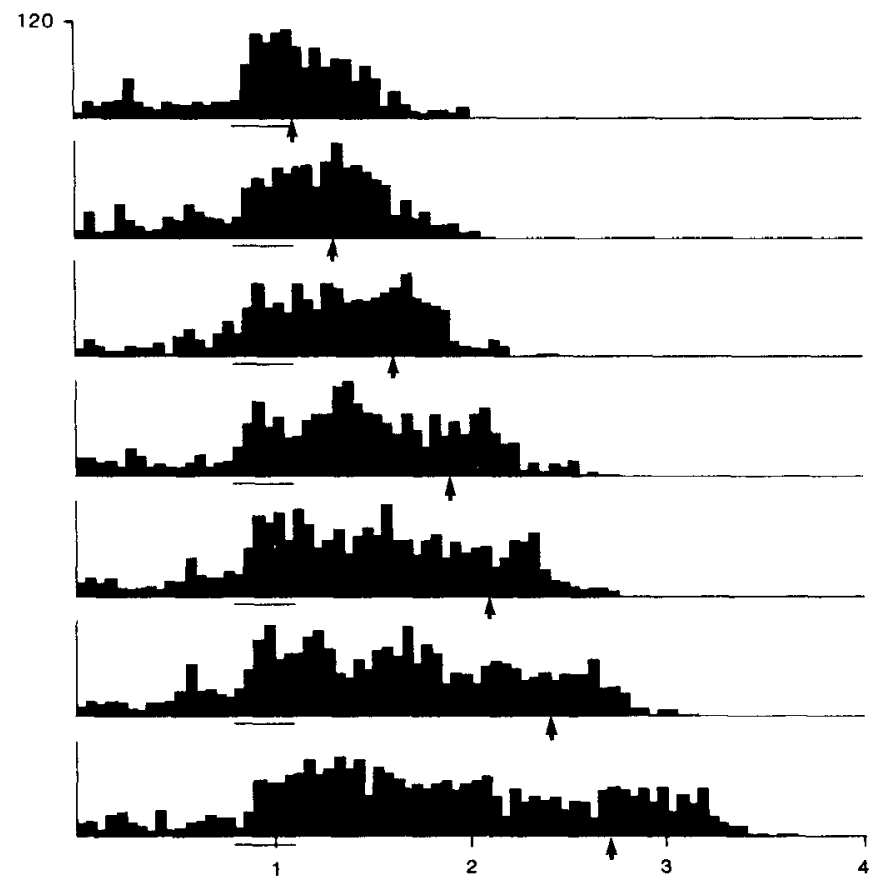

Figure $8 \quad(A)$ Diagram of the sequence of stimulus events in the memory saccade task. $(B)$ Activity histograms of an intended movement cell during saccades to a remembered target location in the cell's motor field. Trials are grouped according to increasing response delay times from top to bottom. The horizontal bar below each histogram indicates the stimulus presentation time. The arrow indicates when the fixation light was extinguished commanding the saccade. From Gnadt \& Andersen (1988). 


\section{CONCLUSION}

This review has covered new findings on the role of the posterior parietal lobe in coordinate transformations for spatial perception and behavior, motion perception, and the processing of saccadic eye movements. The experiments have indicated the distributed nature of the non-retinotopic representation of space in the parietal cortex. The Zipser-Andersen model has been valuable in demonstrating that this spatial representation could be learned. The learning of the associations between visual space and body position is a reasonable hypothesis, since a system for spatial representation would need constant recalibration during growth. Experiments to determine the plasticity of this representation would be most interesting. For instance, distortions of space that result from wearing prisms can be rapidly compensated for by learning (prismatic adaptation). Does this learning result in the cells in area 7a changing their spatial tuning characteristics? Would the Zipser-Andersen model make predictions about changes that may turn up in the recording data as a result of such learning?

Recent experiments indicate that the posterior parietal cortex is at the pinnacle of a presumed hierarchy in motion processing. Area MT feeds motion information into the parietal cortex and has been shown to be part of a motion processing pathway important for perceiving motion. The fast recovery of motion thresholds following MT lesions suggests several experiments on the mechanisms of cortical compensation and reorganization after cerebral lesions. The motion psychophysics/MT lesion paradigm is well suited for asking these questions, since the pathways involved are well understood and the experiments can be rigorously controlled.

Area LIP contains neurons that reflect the intention of the animals to make motor movements. The response properties of these neurons may provide a useful handle for dissecting how motor plans are formulated for sequences of movements and how spatial transformations are recomputed following each movement of a sequence. These problems can bc addressed by observing the dynamic changes in the representation of intended movements in area LIP as animals perform sequences of saccades that are programmed by memorizing sequences of flashed sensory targets.

The results of single cell recording and lesion experiments in the posterior parictal cortex have been instrumental in establishing its role in spatial functions. These same techniques will be able to address, among other issues, how the brain recovers visual-spatial functions after injury, how associations between visual space and body position are learned and stored, and how sequential motor activities are planned and executed. The posterior parietal cortex should prove to be an interesting place for physiologists and anatomists to work in the next few years. 


\section{ACKNOWLEDGMENTS}

I wish to thank C. Andersen for editorial assistance and D. Duffy for typing the manuscript. This work was supported by National Institutes of Health grants EY05522 and EY07492, the Sloan Foundation and the Whitaker Health Sciences Foundation.

\section{Literature Cited}

Albright, R. D., Desimone, R., Gross, C. G. 1984. Columnar organization of directionally selective cells in visual area MT of the macaque. $J$. Neurophysiol. 51: 16-31

Allman, J., Miezen, F., McGuinness, E. 1985. Stimulus specific responses from beyond the classical receptive field: Neurophysiological mechanism for local-global comparisons in visual neurons. Ann. Rev. Neurosci. 8: 407-30

Andersen, R. A. 1987. The role of the inferior parietal lobule in spatial perception and visual-motor integration. In The Handbook of Physiology, Section 1: The Nervous System Volume V, Higher Functions of the Brain Part 2, ed. F. Plum, V. B. Mountcastle, S. R. Geiger, pp. 483-518. Bethesda: Am. Physiol. Soc.

Andersen, R. A., Asanuma, C., Cowan, W. M. 1985 a. Callosal and prefrontal associational projecting cell populations in area $7 \mathrm{a}$ of the macaque monkey: A study using retrogradely transported fluorescent dyes. J. Comp. Neurol. 232: 443-55

Andersen, R. A., Essick, G. K., Siegel, R. M. $1985 \mathrm{~b}$. The encoding of spatial location by posterior parietal neurons. Science 230: 456-58

Andersen, R. A., Siegel, R. M., Essick, G. K., Asanuma, C. 1985c. Subdivision of the inferior parietal lobule and dorsal prelunate gyrus of macaque by connectional and functional critcria. Invest. Ophthalmol. Visual Sci. 23: 266 (Abstr.)

Andersen, R. A., Essick, G. K., Siegel, R. M. 1987. Neurons of area 7 activated by both visual stimuli and oculomotor behavior. Exp. Brain Res. 67: 316-22

Andersen, R. A., Gnadt, J. W. 1988. Role of posterior parietal cortex in saccadic eye movements. Reviews in Oculomotor Research, Vol. 3, ed. R. Wurtz, M. Goldberg. Amsterdam: Elsevier. In press

Andersen, R. A., Siegel, R. M. 1986. Twoand three-dimensional structure from motion sensitivity in monkeys and humans. Soc. Neurosci. Abstr. 12: 1183

Andersen, R. A., Siegel, R. M. 1988. Motion processing in primate cortex. In Signal and
Sense: Local and Global Order in Perceptual Maps, ed. G. M. Edelman, W. E. Gall, W. M. Cowan. New York: Wiley. In press

Andersen, R. A., Zipser, D. 1988. The role of the posterior parietal cortex in coordinate transformations for visual-motor integration. Can. J. Physiol. Pharmacol. 66(4): 488-501

Asanuma, C., Andersen, R. A., Cowan, W. M. 1985. The thalamic relations of the caudal inferior parietal lobule and the lateral prefrontal cortex in monkeys: Divergent cortical projections from cell clusters in the medial pulvinar nucleus. $J$. Comp. Neurol. 241: 357-81

Baleydier, C., Mauguiere, R. 1980. The duality of the cingulate gyrus in monkey. Neuroanatomical study and functional hypothesis. Brain 103: 525-54

Barbas, H., Mesulam, M. M. 1981. Organization of afferent input to subdivisions of area 8 in the rhesus monkey. J. Comp. Neurol. 200: 407-31

Benevento, L. A., Fallon, J. H. 1975. The ascending projections of the superior colliculus in the rhesus monkey (Macaca mulatta). J. Comp, Neurol. 160: 339-62

Benevento, L. A., Rezak, M., Santos-Anderson, R. 1977. An autoradiographic study of the projections of the pretectum in the rhesus monkey (Macaca mulatta): Evidence of sensorimotor links to the thalamus and oculomotor nuclei. Brain Res. 127: 197218

Benevento, L. A., Standage, G. P. 1983. The organization of projections of the retinorecipient and non-retinorecipient nuclei of the pretectal complex and layers of the superior colliculus to the lateral pulvinar and medial pulvinar in the macaque monkey. J. Comp. Neurol. 217: 307-36

Bioulac, B., Lamarte, Y. 1979. Activity of postcentral cortical neurons of the monkey during conditioned movements of a deafferented limb. Brain Res. 172: 427-37

Bisiach, E., Luzzatti, C. 1978. Unilateral neglect of representational space. Cortex 14: $129-33$ 
Brodmann, K, 1905. Beitrage zür histologischen localisation der grosshirnrinde, dritte mitteilung: Die rinderfelder der niederen affen. $J$. Psychol. Neurol. 4: 177 . 226

Colby, C. L., Olson, C. R. 1985. Visual topography of cortical projections to monkey superior colliculus. Soc. Neurosci. Abstr. 11: 1244

Dursteler, M. R., Wurtz, R. H., Yamasaki, D. S. 1986. Pursuit and OKN deficits following ibotenic acid lesions in the medial superior temporal area (MST) of monkey. Soc. Neurosci. Abstr. 12: 1182

Frost, B. J., Nakayama, K. 1985. Single visual neurons code opposing motion independent of direction. Science 13(220): $744-45$

Gnadt, J. W., Andersen, R. A. 1986. Spatial, memory, and motor-planning properties of saccade-related activity in the lateral intraparietal area (LIP) of macaque. Soc. Neurosci. Abstr. 13:454

Gnadl, J. W., Andersen, R. A. 1988. Memory related motor planning activity in posterior parietal cortex of macaque. Exp. Brain Res. 70: 216-20

Goldman-Rakic, P. S. 1988. Topography of cognition: Parallel distributed networks in primate association cortex. Ann. Rev. Neurosci. 11: 137-56

Golomb, B., Andersen, R. A., Nakayama, K., MacLeod, D. I. A., Wong, A. 1985. Visual thresholds for shearing motion in monkey and man. Vision Res. 25: 813-20

Harting, J. K., Huerta, M. F., Frankfurter, A. J., Strominger, N. L., Royce, F. J. 1980. Ascending pathways from the monkey superior colliculus: An autoradiographic analysis. J. Comp. Neurol. 192: 853-82

Hyvarinen, J. 1981. Regional distribution of functions in parietal association area 7 of the monkey. Brain Res. 206: 287-303

Hyvarinen, J., Shelepin, Y. 1979. Distribution of visual and somatic functions in the parietal associative area 7 of the monkey. Brain Res. 169: 561-64

Lynch, J. C., Graybiel, A. M., Lobeck, L. J. 1985. The differential projection of two cytoarchitectural subregions of the inferior parietal lobule of macaque upon the deep layers of the superior colliculus. J. Comp. Neurol. 235: 241-54

Lynch, J. C., Mounteastle, V. B., Talbot, W. H., Yin, T. C. T. 1977. Parietal lobe mechanisms for directed visual attention. J. Neurophysiol. 40: 362-89

Maunsell, J. H. R., Van Essen, D. C. 1983. The connections of the middle temporal visual area (MT) and their relationship to a cortical hierarchy in the macaque monkey. J. Neurosci. 3: 2563-86

Motter, B. C., Mountcastle, V. B. 1981. The functional properties of the light-sensitive neurons of the posterior parietal cortex studied in waking monkeys: Foveal sparing and opponent vector organization. $J$. Neurosci. 1: 3-26

Mountcastle, V. B., Lynch, J. C., Georgopoulos, A., Sakata, H., Acuna, C. 1975. Posterior parietal association cortex of the monkey: Command function for operations within extrapersonal space. J. Neurophysiol. 38: 871-908

Movshon, J. A. 1985. Processing of motion information by neurons in the striate extrastriate visual cortex of the macaque. Invest. Ophthalmol. Vis. Sci. 26S: 133

Movshon, J. A., Adelson, E. H., Gizzi, M. S., Newsome, W. T. 1985. The analysis of moving visual patterns. Exp. Brain Res. 11: 117-51 (Suppl.)

Nakayama, K. 1981. Differential motion hyperacuity under conditions of common image motion. Vision Res. 21: 1475-82

Nakayama, K. Silverman, G., MacLeod, D. I. A., Muligan, J. 1985. Sensitivity to shearing and compressive motion in random dots. Perception 14(2): 225-38

Nakayama, K., Tyler, C. W. 1981. Psychophysical isolation of movement sensitivity by removal of familiar position cues. Vision Res. 21: 427-33

Newsome, W. T., Pare, E. B. 1986. MT lesions impair discrimination of direction in a stochastic motion display. Neurosci. Abstr. 12: 1183

Newsome, W. T., Pare, E. B. 1988. A selective impairment of motion perception following lesions of the middle temporal visual area (MT). J. Neurosci. In press

Newsome, W. T., Wurtz, R. H., Dursteler, M. R., Mikami, A. 1985. The middle temporal visual area of the macaque monkey. Deficts in visual motion processing following ibotenic acid lesions in MT. $J$. Neurosci. 5: 825-40

Orban, G. A., Spileers, W., Gulyas, B., Bishop, P. O. 1986. Motion in depth selectivity of cortical cells revisited. Soc. Neurosci. Abstr. 12: 584

Pandya, D. A., Van Hoesen, G. W., Mesulam, M. M. 1981. Efferent connections of the cingulate gyrus in the rhesus monkey. Exp. Brain Res. 42: 319-30

Robinson, C. J., Burton, H. 1980a. Organization of somatosensory receptive fields in cortical areas $7 \mathrm{~b}$, retroinsular postauditory and granular insula of $M$. fascicularis. J. Comp. Neurol. 192: 69 92

Robinson, C. J., Burton, H. 1980b. Somatic submodality distribution within the second somatosensory (SII), 7b, retroinsular postauditory, and granular insular cortical areas of M. fascicularis. J. Comp. Neurol. 192: 93-108 
Robinson, D. L., Goldberg, M. E., Stanton, G. B. 1978. Parietal association cortex in the primate: Sensory mechanisms and behavioral modulations. J. Neurophysiol. 41: $910-32$

Rockland, K. S., Pandya, D. N. 1979. Laminar origins and terminations of cortical connections of the occipital lobe in the rhesus monkey. Brain Res. 179: 3-20

Rogers, B., Graham, M. 1979. Motion parallax as an independent cue for depth perception. Perception 8: 125-34

Rogers, B., Graham, M. 1982. Similarities between motion parallax and stereopsis in human depth perception. Vision Res. 22; $261-70$

Saito, H., Yukio, M., Tanaka, K., Hikosaka, K., Fukada, Y., Iwai, E. 1985. Integration of direction signals of image motion in the superior temporal sulcus of the macaque monkey. .J. Neurosci. 6: 145-57

Sakata, H., Shibutani, H., Kawano, K. 1980. Spatial properties of visual fixation neurons in posterior parietal association cortex of the monkey. J. Neurophysiol. 43: 1654-72

Sakata, H., Shibutani, H., Kawano, K. 1983. Functional properties of visual tracking neurons in posterior parietal association cortex of the monkey. J. Neurophysiol. 49: 1364-80

Sakata, H., Shibutani, H., Kawano, K., Harrington, T. 1985. Neural mechanisms of space vision in the parietal association cortex of the monkey. Vision Res. 25: 45364

Sakata, H., Yukio, M., Tanaka, K., Hikosaka, K., Fukada, Y., Iwai, E. 1986. Integration of direction signals of image motion in the superior temporal sulcus of the macaque monkey. $J$. Neurosci. $6: 145$ 57

Seal, J., Commenges, D. 1985. A quantitative analysis of stimulus and movement-related responses in the posterior parietal cortex of the monkey. Exp. Brain Res. 58: 144-53

Seal, J., Gross, C., Bioulac, B. 1982. Activity of neurons in area 5 during a simple arm movement in monkeys before and after deafferentation of trained limb. Brain Res. 250: 229-43

Seltzer, B., Pandya, D. N. 1984. Further observations on parieto-temporal connections in the rhesus monkey. Exp. Brain Res. 5: 301-12

Shubutani, H., Sakata, H., Hyvarinen, J. 1984. Saccade and blinking cvoked by microstimulation of the posterior parietal association cortex of the monkey. Exp. Brain Res. 55: 1-8

Siegel, R. M., Andersen, R. A. 1986. Motion perceptual deficits following ibotenic acid lesions of the middle temporal area (MT) in the behaving rhesus monkey. Soc. Neurosci. Abstr. 12: 1183

Siegel, R. M., Andersen, R. A. 1988. Perception of three-dimensional structure from two-dimensional visual motion in monkey and man. Nature 331(6153): 25961

Siegel, R. M., Andersen, R. A., Essick, G. K., Asanuma, C. 1985. The functional and anatomical subdivision of the inferior parietal lobule. Soc. Neurosci. Abstr. 11: 1012

Tanaka, K., Hikosaka, K., Saito, H., Yuki, M., Fukada, Y., Iwai, E. 1986. Analysis of local and wide-field movements in the superior temporal visual areas of the macaque monkey. J. Neurosci. 6: 134 44

Trojanowski, J. Q., Jacobson, S. 1975. Peroxidase labeled subcortical afferents to pulvinar in rhesus monkey. Brain Res. 97: 144-50

Ullman, S. 1979. The Interpretation of Visual Motion. Cambridge, Mass: MIT Press

Ullman, S. 1984. Maximizing rigidity: The incremental recovery of 3-D structure from rigid and nonrigid motion. Perception 13: 255-74

Ungerleider, L. G., Desimone, R. 1986. Cortical connections of visual area MT in the macaque. J. Comp. Neurol. 248: 190222

Vogt, C., Vogt, O. 1919. Allgemeine Ergebnisse unserer hirnforschung. J. Psychol. Neurol. 25: 279-462

von Bonin, G., Bailey, P. 1947. The Neocortex of Macaca Mulatta. Urbana: Univ. Illinois Press

Wurtz, R. H., Newsome W. T. 1985. Divergent signals encoded by neurons in extrastriate areas MT and MST during smooth pursuit eye movements. Soc. Neurosci. Abstr. 11: 1246

Yeterian, E. H., Pandya, D. N. 1985. Corticothalamic connections of the posterior parietal cortex in the rhesus monkey. J. Comp. Neurol. 237: 408-26

Zipser, D., Andersen, R. A. 1988. A back propagation programmed network that simulates response properties of a subset of posterior parietal neurons. Nature 331: 679-84 
Annual Review of Neuroscience
Volume 12,1989

\section{CONTENTS}

The Journey of A Neuroembryologist, Viktor Hamburger 1

Short-Term Synaptic Plasticity, Robert S. Zucker 13

InTEGrating With NeUrons, $D . A$. Robinson 33

Immortalization of Neural Cells via Retrovirus-Mediated Oncogene Transduction, Constance L. Cepko 47

Structure of the Adrenergic and Related Receptors, Brian $F$. O'Dowd, Robert J. Lefkowitz, and Marc G. Caron 67

Long-Term Depression, Masao Ito 85

Novel NeUrotrophic Factors, Receptors, and ONCOGENES, Patricia Ann Walicke 103

Axonal Growth-Associated Proteins, J. H. Pate Skene 127

Learning Arm Kinematics and Dynamics, Christopher $G$. Atkeson 157

Emerging Principles Governing the Operation of Neural NeTworks, Peter A. Getting

The Function of Synaptic Transmitters in the Retina, Nigel W. Daw, William J. Brunken, and David Parkinson 205

Fluorescent Probes of Cell Signaling, Roger Y. Tsien 227

INVOLVEMENT OF HORMONAL AND NEUROMODULATORY SySTEMS IN the Regulation of Memory Storage, James L. McGaugh 255

Cyclic GMP-Activated Conductance of Retinal PhotoreCePtor Cells, K.-W. Yau and D. A. Baylor 289

The Cell Biology of Vertebrate Taste Receptors, Stephen $D$. Roper

Startle, Categorical Response, and Attention in Acoustic BeHAVIOR OF InSECTS, Ronald R. Hoy

Visual and Eye Movement Functions of the Posterior Parietal CORTEX, Richard A. Andersen 
vi CONTENTS (Continued)

SPIDER Toxins: Recent APPLICATIONS IN NEUROBIOLOGY, Hunter Jackson and Thomas N. Parks

Acute Regulation of Tyrosine Hydroxylase by Nerve ACtivity and by Neurotransmitters via Phosphorylation, Richard E. Zigmond, Michael A. Schwarzschild, and Ann R. Rittenhouse

Biochemistry of Altered Brain Proteins in Alzheimer's Disease, Dennis J. Selkoe

Extracellular Matrix Molecules that Influence Neural Development, Joshua $R$. Sanes

The Macroglial Cells of the Rat Optic Nerve, Robert H. Miller, Charles ffrench-Constant, and Martin C. Raff

INDEXES

Subject Index

Cumulative Index of Contributing Authors, Volumes 8-12 